Check for updates

Cite this: RSC Adv., 2018, 8, 30430

\section{An efficient and environmentally sustainable domino protocol for the synthesis of structurally diverse spiroannulated pyrimidophenazines using erbium doped $\mathrm{TiO}_{2}$ nanoparticles as a recyclable and reusable heterogeneous acid catalyst $\uparrow$}

\author{
Kanchan Verma, ${ }^{a}$ Yogesh Kumar Tailor, ${ }^{a}$ Sarita Khandelwal, ${ }^{a}$ Monu Agarwal, ${ }^{a}$ \\ Esha Rushell, ${ }^{a}$ Yogita Kumari, ${ }^{b}$ Kamlendra Awasthi ${ }^{b}$ and Mahendra Kumar iD *a
}

\begin{abstract}
An efficient and environmentally sustainable domino protocol has been presented for the synthesis of structurally diverse spiroannulated pyrimidophenazines involving a four component reaction of 2hydroxynaphthalene-1,4-dione, benzene-1,2-diamine, cyclic ketones and amino derivatives in the presence of erbium doped $\mathrm{TiO}_{2}$ nanoparticles as a recyclable and reusable heterogeneous acid catalyst. The present synthetic protocol features mild reaction conditions with operational simplicity, excellent yield with high purity, short reaction time and high atom economy with the use of a recoverable and reusable environmentally sustainable heterogeneous catalyst.
\end{abstract}

Received 8th June 2018

Accepted 22nd August 2018

DOI: $10.1039 / \mathrm{c} 8 \mathrm{ra04919j}$

rsc.li/rsc-advances

and their support. ${ }^{10-12}$ The catalytic efficiency, selectivity, and recyclability of nanostructured catalysts depend on the size, shape, composition, and assembly of the NPs, as well as their interaction with the support. The heterogeneous catalytic processes based on mixed metal oxide catalysts received considerable attention and was utilized successfully in organic transformations including heterocyclic synthesis and green synthetic protocols. ${ }^{13-15}$ The design and development of an efficient, green, sustainable and economical synthetic protocol is one of the major challenges in chemical research. The catalysis with nanostructured catalyst is considered as a significant option for multicomponent reactions in view of efficient and selective catalytic reactions with the waste reduction, atomic efficiency and catalyst recovery. ${ }^{16}$ Titanium dioxide $\left(\mathrm{TiO}_{2}\right)$ catalysis is considered very close to an ideal catalysis because of its sustainability and environmental concerns. ${ }^{11,15,17-20}$ In recent years, $\mathrm{TiO}_{2}$ NPs have emerged as efficient and inexpensive heterogeneous catalyst to promote organic transformations. $^{21}$

Phenazines are versatile building blocks and encountered in bioactive natural products (Fig. 1(i-vi)) and synthesized pharmaceuticals. $^{22,23}$ Phenazines have been reported to exhibit a wide spectrum of biological activities including anticancer, ${ }^{24}$ (Fig. 1(iv)) antimalarial, ${ }^{25}$ (Fig. 1(v)) antiplasmodial, ${ }^{26}$ antibacterial, ${ }^{27}$ antifungal, ${ }^{28}$ cancer chemopreventive, ${ }^{29}$ antichagas agent $^{30}$ and antiparasitic activities (Fig. 1), ${ }^{31}$ in addition to their uses in the preparation of industrial dyes, and fluorescent or electro-active markers in biological systems. ${ }^{32}$ Benzophenazines have shown dual inhibition of topoisomerase I and II, two key enzymes influencing DNA topology at different points in the cell 
<smiles></smiles>

Benthocyanin A

(i)<smiles>C/C=C\C=C/CNC(=O)c1cccc2nc3ccc4ccccc4c3nc12</smiles>

Anticancer

(iv)<smiles>C=C1CCCC(C)(C)[C@H]1CC/C(C)=C/Cn1c2cccc(=O)c-2nc2ccccc21</smiles>

Phenazinomycin

(ii)<smiles>Oc1ccc2ccccc2c1-c1cc2nc3ccccc3nc2c2ccccc12</smiles>

Antimalarial

(v)<smiles>COc1ccc(COC(=O)CO)c2nc3cccc(C(=O)O)c3nc12</smiles>

Griseolutein A

(iii)<smiles>Cc1cccc(O)c1C(=O)OC(C)c1cccc2nc3c(C(=O)O)cccc3nc12</smiles>

Saphenamycin

(vi)

Fig. 1 Biologically active phenazines.

cycle. ${ }^{24,33-36}$ The fluorescent phenazine derivatives have been considered as photosensitizers in photodynamic therapy $(\mathrm{PDT})^{37-39}$ in which the combination of light and photosensitizer creates highly reactive oxygen species near the tumour to selectively destroy the targeted tissue.

Pyrimidine-fused heterocycles with wide range of biological activities are extensively being used in the design of new drugs. ${ }^{40}$ Pyrimido-pyrimidine derivatives have attracted considerable interest due to their tyrosine kinase inhibitory activity, ${ }^{41}$ antitumor activity, ${ }^{\mathbf{4 2}}$ antiviral effect, ${ }^{\mathbf{4 3}}$ and antioxidant properties. ${ }^{44}$ Pyridopyrimidines are also privileged scaffolds and reported to exhibit wide spectrum of activities including antitumor, antiallergic, antifolate, antimicrobial, calcium channel antagonist, antibacterial, antiinflammatory, analgesic, antihypertensive, antileishmanial, anticonvulsant, and diuretic. ${ }^{45-47}$ Pyridopyrimidine constitutes the core structure of some<smiles>Cc1cc2nc3c4ccccc4n(CCN(C)C)c3nc2cc1C</smiles>

(I)<smiles>O=S(=O)(Cl)c1ccc2nc(-c3ccccc3)c(-c3ccccc3)nc2c1</smiles>

(iv)<smiles>[R]CNC(=O)c1ccc2nc(-c3ccco3)c(-c3ccco3)nc2c1</smiles>

Antiviral

(II)<smiles>C=C(C)OC(=O)N1c2ccccc2NC(=S)C1(C)C</smiles>

Antiviral

(III)<smiles>[R]C1=CC=CC(Cc2nc3ccccc3[nH]c2=O)C=C1</smiles>

Antifungal

(v)

Fig. 2 Biologically active quinoxalines. 


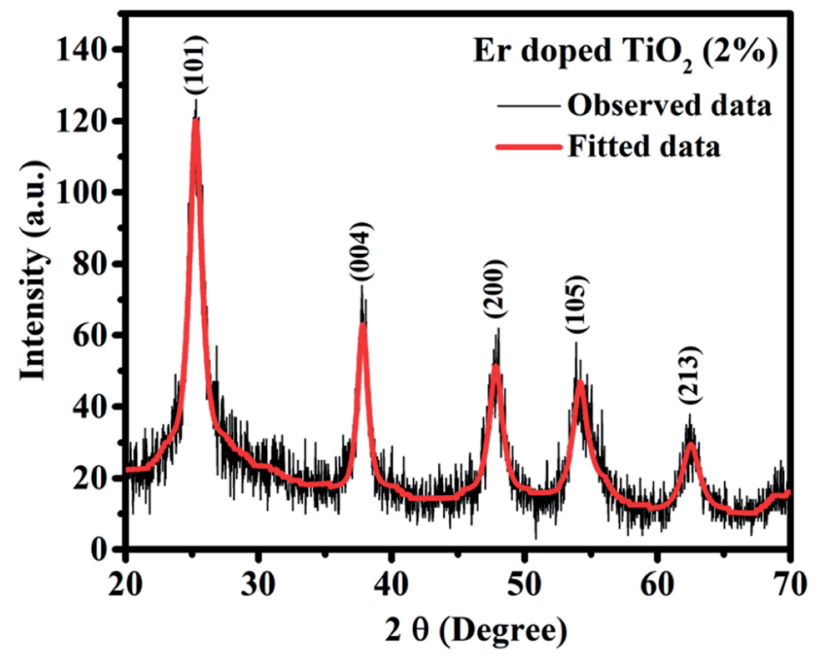

Fig. 3 XRD pattern of Er doped $\mathrm{TiO}_{2}$ (2\%) NPs.

marketed drugs, including the antiasthmatic agent pemirolast, ${ }^{48}$ the tranquilizer pirenperone ${ }^{49}$ and the antiallergic agent barmastine. $^{50}$

Quinoxaline derivatives have also been reported to exhibit a broad spectrum of biological activities, such as antibacterial, ${ }^{51,52}$ antifungal,${ }^{53}$ antiviral, ${ }^{54}$ anticancer, ${ }^{55}$ anti-tubercular, ${ }^{53}$ antimalarial $^{56}$ and anti-inflammatory ${ }^{54}$ (Fig. 2). Quinoxaline derivatives have also been reported to inhibit selectively the platelet-derived growth factor (PDGF) receptor kinase, PDGFdependent DNA synthesis in cell lines and inhibit the human cancer cell lines. ${ }^{57}$

In view of pharmaceutical importance of phenazines, pyrimidines and quinoxalines as medicinally privileged heterocyclic scaffolds and our continuing research interest in the synthesis of drug-like molecules with structural diversity and molecular complexity incorporating privileged structures, ${ }^{58-61}$ we are concerned with the development of an efficient and sustainable domino protocol for the synthesis of therapeutically interesting hybrid molecules, spiroannulated pyrimidophenazines, incorporating three-four medicinally privileged heterocyclic systems in a single molecule. The conventional synthetic strategies of phenazines usually involve multistep reaction sequences, which suffer from disadvantages including several synthetic steps, harsh reaction conditions, use of toxic organic solvents, high reaction time, low yields, and tedious isolation and purification of the resulting products. ${ }^{31}$ Multicomponent reactions (MCRs) with pot-economy are considered superior to the conventional multi-steps synthetic strategy, and offer a convenient approach for the rapid synthesis of complex molecules. Benzo[a]phenazines were synthesized by using $p$-TSA (10 mol\%)/PEG-400 reaction medium via one-pot four-component protocol. ${ }^{38}$ Microwave-assisted MCRs have also been used for the synthesis of benzopyranophenazines. ${ }^{62-64}$ Benzo $[a]$ pyrano $[2,3-c]$ phenazines were also synthesized with the use of AcOH ${ }^{65,66}$ caffeine, ${ }^{62}$ theophylline, ${ }^{67}$ DABCO ${ }^{63,68}$ pyridine, ${ }^{69}$ PTSA $^{70}{ }^{7 o n i c-l i q u i d,}{ }^{71}$ oxalic acid, ${ }^{72}$ bifunctional thiourea-based organocatalyst $^{73}$ and nano-copper(II) oxide

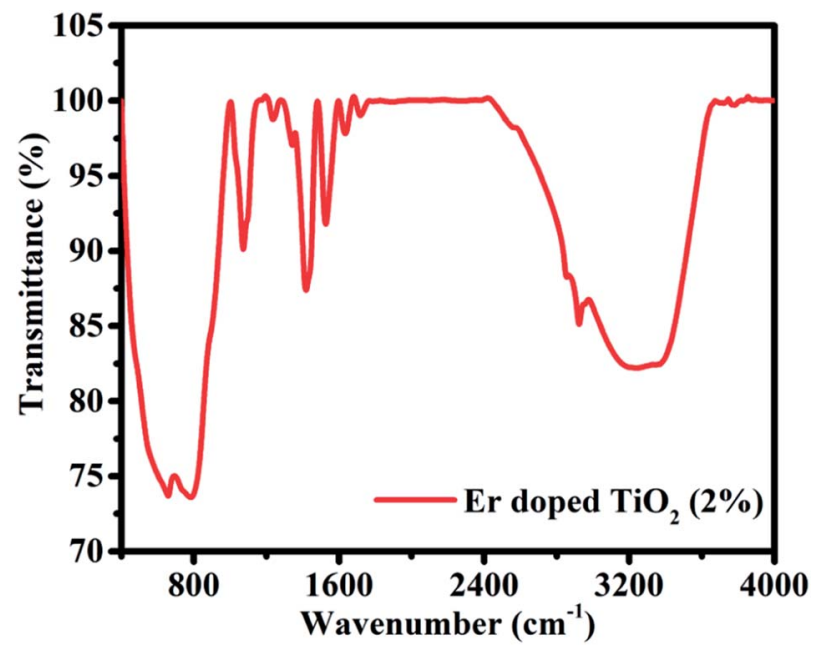

Fig. 4 FTIR spectra of Er doped $\mathrm{TiO}_{2}(2 \%) \mathrm{NPs}$.

catalyzed MCRs. But it has been observed that the synthetic strategy to synthesize spirocyclic hybrid molecules with privileged heterocyclic substructures has not been reported in the literature. The present synthetic protocol is probably the first report for the synthesis of spiroannulated pyrimidophenazines, drug-like complex molecules, using nanostructured erbium (Er) doped $\mathrm{TiO}_{2}$ as heterogeneous solid acid catalyst.

\section{Results and discussion}

In the present work, we have presented highly efficient and diversity oriented sustainable synthetic protocol to synthesize spirocyclic hybrid molecules, pyrimidophenazines with privileged heterocyclic substructures, involving four component reaction of 2-hydroxynaphthalene-1,4-dione, benzene-1,2diamine, cyclic ketone and amino derivatives in the presence of erbium doped $\mathrm{TiO}_{2}$ NPs as recyclable and reusable heterogeneous acid catalyst.

\section{Preparation and characterization of catalyst}

Er doped $\mathrm{TiO}_{2}$ NPs were synthesized by sol-gel method and characterized by X-ray diffraction (XRD) (X'pert pro-Panalytical, $\mathrm{Cu}-\mathrm{K} \alpha, 1.54 \AA$ Å), Fourier transform infrared spectroscopy (FTIR) (Perkin2Elmer $4000-400 \mathrm{~cm}^{-1}$ ), Transmission electron microscopy (TEM) (Technai T20 FEI), and Energy dispersive X-ray spectroscopy (EDX).

Fig. 3 shows XRD pattern of Er doped $\mathrm{TiO}_{2}(2 \%)$ NPs and confirms the crystalline behaviour of synthesized NPs. The peaks at the angle of $2 \theta=25.25^{\circ}, 37.80^{\circ}, 47.79^{\circ}, 54.12^{\circ}$, and $62.45^{\circ}$ are corresponding to reflections from the planes (101), (004), (200), (105), and (213) respectively. All the planes correspond to the anatase phase of $\mathrm{TiO}_{2}$ and matched with the JCPDS card no. 00-021-1272. Absence of any peak other than $\mathrm{TiO}_{2}$ indicates the absence of any compound with $\mathrm{Er}$ and it is doped in $\mathrm{TiO}_{2}$ substitutionally or interstitially. The mismatching of the radii of the $\mathrm{Er}^{3+}$ and $\mathrm{Ti}^{4+}$ prevents the $\mathrm{Er}^{3+}$ ions to enter into the $\mathrm{TiO}_{2}$ lattice. So, the substitution of $\mathrm{Ti}^{4+}$ with $\mathrm{Er}^{3+}$ and the 

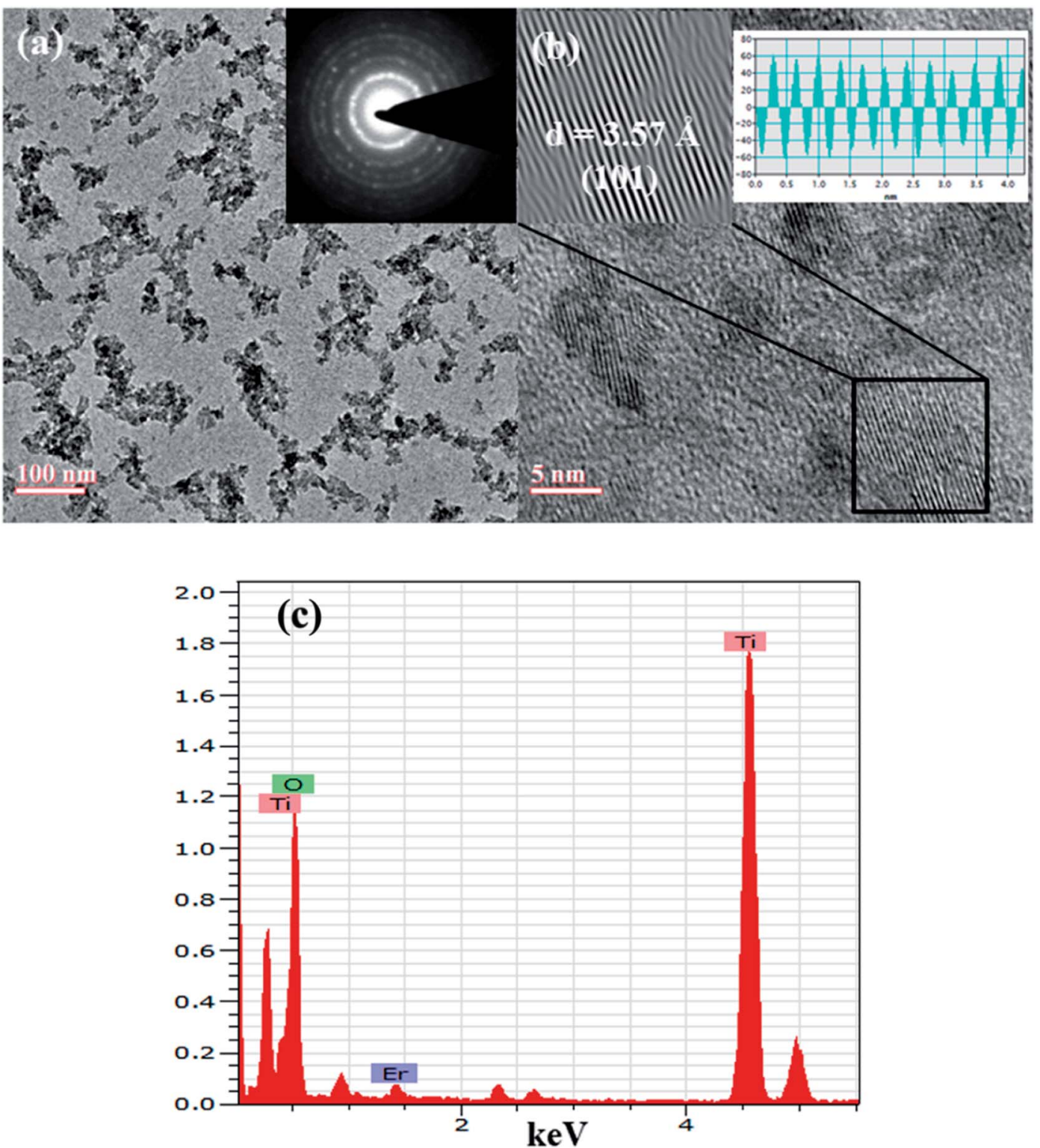

Fig. 5 TEM image, SAED pattern (inset) (a), HRTEM image of lattice planes, IFFT and profile of IFFT (b), and EDX (c) of Er doped TiO 2 (2\%) NPs.

formation of Ti-O-Er bonds are expected which was further investigated by FTIR. The broadening and FWHM (full width at half maximum) of the peaks suggests the size of NPs in the range of nanoscale and the particles size was calculated by Debye-Scherrer formula.

$$
d=\frac{0.9 \lambda}{\beta \cos \theta}
$$

where, $d$ represents the size of the NPs. $\lambda, \beta$, and $\theta$ are the wavelength of X-rays incident on the sample, FWHM and angle

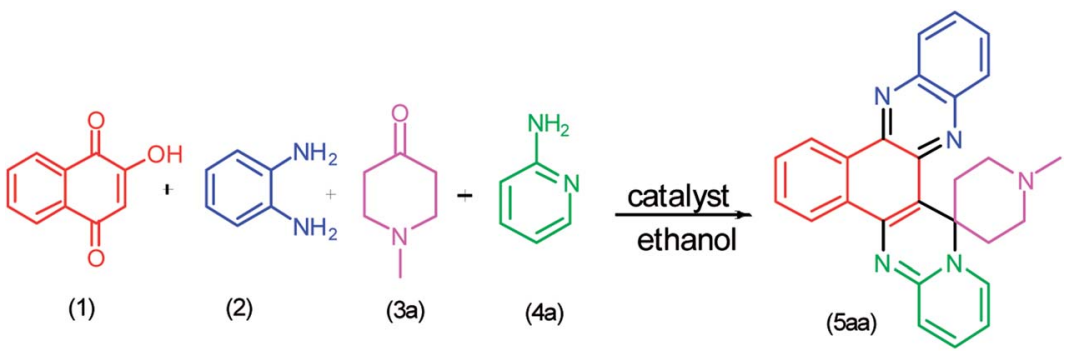

Scheme 1 Model reaction. 
Table 1 Optimization of reaction conditions ${ }^{a, b}$

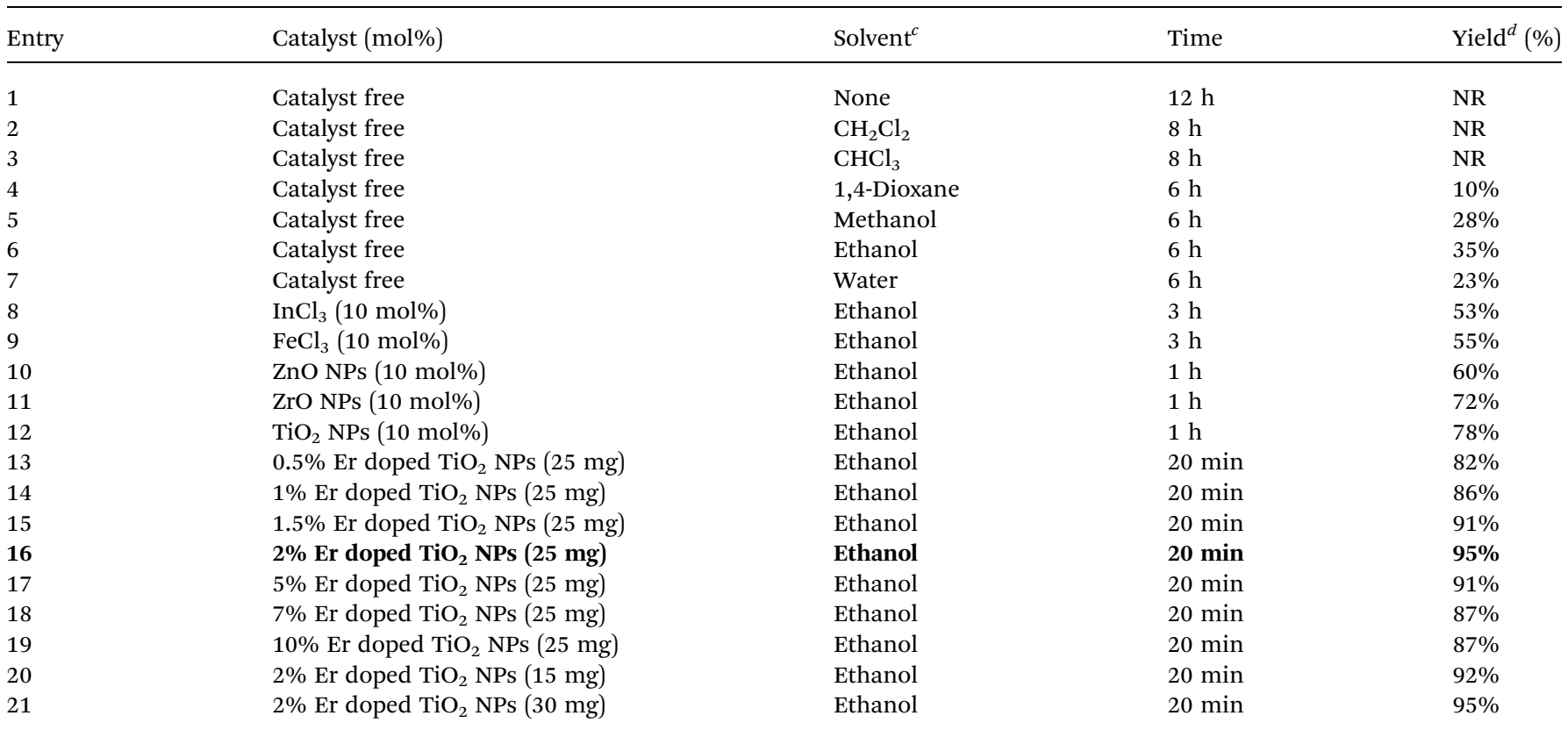

${ }^{a}$ Bold row indicates the optimization condition for the reaction. ${ }^{b}$ 2-Hydroxynaphthalene-1,4-dione $(1 \mathrm{mmol})$, benzene-1,2-diamine $(1 \mathrm{mmol}), N$ methyl-4-piperidone $(1 \mathrm{mmol})$ and 2 -aminopyridine $(1 \mathrm{mmol})$ were stirred with refluxing till completion of the reaction as indicated by TLC. ${ }^{c}$ Solvents $(2.0 \mathrm{ml}){ }^{d}$ Isolated yield after purification.

of diffraction respectively. The average particle size was calculated as $\sim 7.5 \mathrm{~nm}$.

FTIR spectrum of Er doped $\mathrm{TiO}_{2}$ NPs is shown in Fig. 4. The bands observed from 400 to $1000 \mathrm{~cm}^{-1}$ correspond to the lattice vibrations of $\mathrm{Ti}-\mathrm{O}$, and $\mathrm{Ti}-\mathrm{O}-\mathrm{Ti}$ in $\mathrm{TiO}_{2}$ lattice. The vibrations corresponding to Ti-O-Er bonds also occur in the same region. The presence of Er was further confirmed by EDX. The peak at $1071 \mathrm{~cm}^{-1}$ may be assigned to the bond S-O which is expected to occur from thioglycerol used as capping agent. The bands observed from $1200-1800 \mathrm{~cm}^{-1}$ and a broad band at $3235 \mathrm{~cm}^{-1}$ may be ascribed to the bending vibrations of water molecules adsorbed on the surface of NPs and the stretching vibrations of hydroxyl ions $(\mathrm{O}-\mathrm{H})$.

Morphological behaviour of NPs was examined by TEM and shown in Fig. 5. The shape of the NPs from Fig. 5(a) seems to be spherical however the NPs are found to be agglomerated. The size of the NPs from TEM image is consistent with the XRD results. Inset of Fig. 5(a) shows the SAED pattern of the NPs consisting of a number of rings. These rings indicate the polycrystalline behaviour of the NPs. From the analysis of HRTEM image (Fig. 5(b)) of NPs, $d$ spacing of (101) plane was found to be $3.57 \AA$. Inset of Fig. 5(b) shows the inverse FFT and the profile of inverse FFT to calculate the $d$ spacing. The presence of $\mathrm{Er}$ in Er doped $\mathrm{TiO}_{2}$ NPs was confirmed by EDX spectra shown in Fig. 5(c).

\section{Optimization of reaction conditions}

Initially, four-component reaction of 2-hydroxynaphthalene-1,4dione (1), benzene-1,2-diamine (2), $N$-methyl-4-piperidone (3a) and 2-aminopyridine (4a) was selected as a simple model reaction to establish the feasibility of the present synthetic strategy and to optimize the reaction conditions (Scheme 1).
The multicomponent reaction was carried out under catalyst and solvent free conditions, but the reaction was not successful and did not provide the desired product (no result) (Table 1, entry 1). We have used different solvents in the reaction, but ethanol was found to be the solvent of choice (Table 1, entries 27). The model reaction was also performed in the presence of $\mathrm{InCl}_{3}$ and $\mathrm{FeCl}_{3}$ in ethanol as solvent, but the desired product was obtained in moderate yield (Table 1, entries 8 and 9). The reaction was then screened with $\mathrm{ZnO}, \mathrm{ZrO}$ and $\mathrm{TiO}_{2}$ nanocatalysts using ethanol as solvent and observed that the reaction catalyzed by $\mathrm{TiO}_{2}$ NPs provided comparatively better result as compared with those obtained with the use of $\mathrm{ZnO}$ and $\mathrm{ZrO}$ nanocatalysts (Table 1, entry 10-12). But when the reaction was carried out with the use of Er doped $\mathrm{TiO}_{2}$ NPs in the presence of ethanol, the encouraging results were obtained (Table 1, entry 13-21). Moreover, the effect on catalyst activity with the range of Er doping with $\mathrm{TiO}_{2}$ NPs was also investigated. To find out the ideal doping of erbium on $\mathrm{TiO}_{2} \mathrm{NPs}$ with reference to catalyst activity, the reactions with $0.5 \%, 1 \%, 1.5 \%, 2 \%, 5 \%, 7 \%$, and $10 \%$ erbium doped $\mathrm{TiO}_{2}$ were performed under similar conditions and observed that $0.5 \%, 1 \%$ and $1.5 \%$ Er doped $\mathrm{TiO}_{2}$ nanocatalysts provided $82 \%, 86 \%$ and $91 \%$ yields respectively in 20 minutes (Table 1, entry 13-15). As evident from the reaction results, $2 \%$ erbium doping provided the best result with $95 \%$ yield in 20 minutes (Table 1, entry 16), while erbium doping (5\%, 7\% and 10\%) provided slightly decreased yield (91-87\%) (Table 1, entry 17-19). The effect of catalyst loading on efficiency on catalyst was also examined and observed that $25 \mathrm{mg}$ loading of erbium doped $\mathrm{TiO}_{2} \mathrm{NPs}$ was optimal and provided excellent yield of the product (Table 1, entry 20 and 21). The higher loading of catalyst did not noticeably improve the yield. Thus, with the optimized reaction conditions, we explored the 
Table 2 Synthesis of spiroannulated pyrimidophenazines

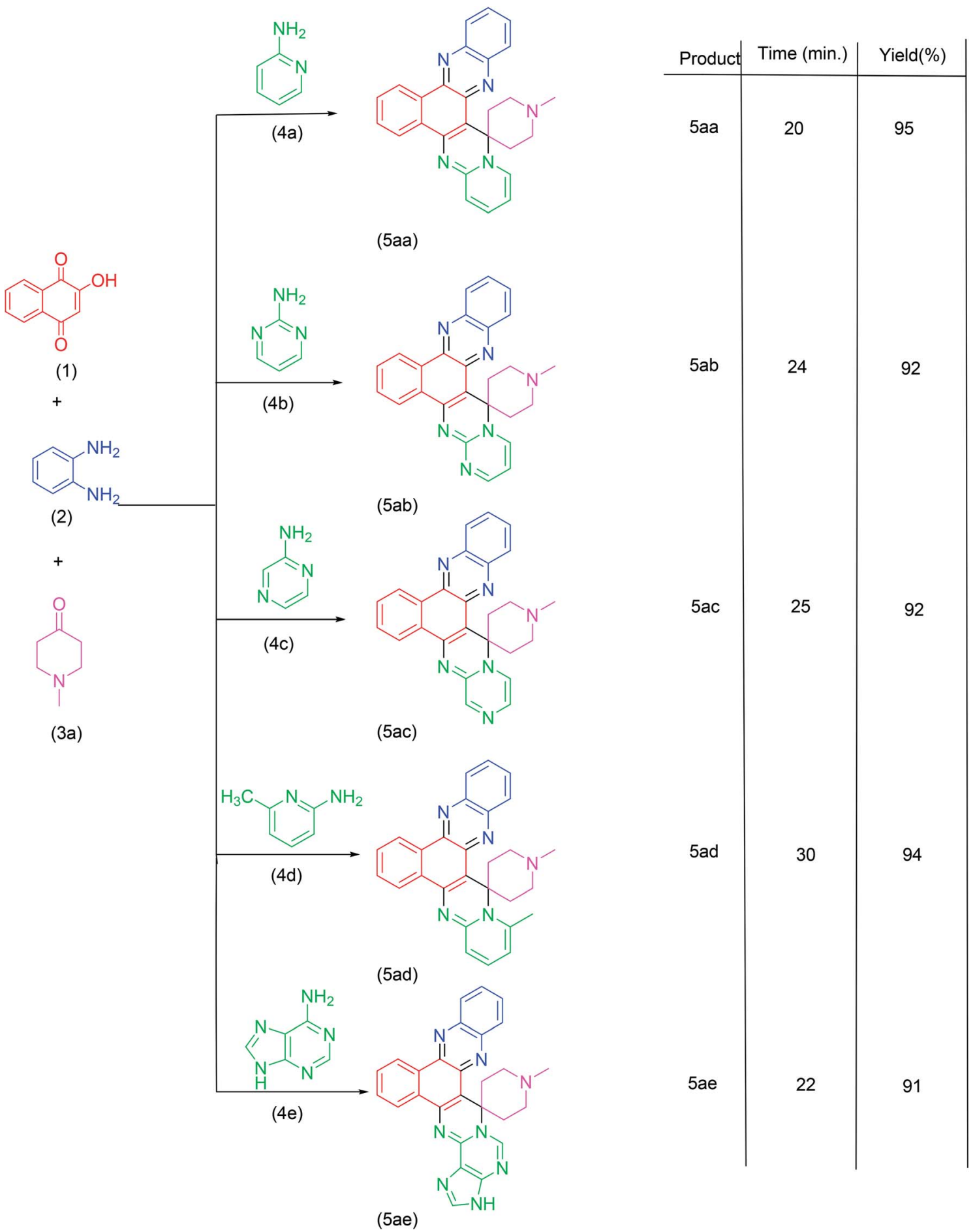

generality and scope of the present synthetic strategy with different building blocks and synthesized the library of spiroannulated pyrimidophenazines. To our delight, the reactions proceed smoothly and structurally diverse spiroannulated pyrimidophenazines were obtained in excellent yields. The results are summarized in Tables 2-4.

Additionally, the catalytic recyclability and reusability was also investigated on the model reaction under optimized reaction conditions. After each cycle, the reaction was followed by extraction of products and catalyst. The collected catalyst was washed with methanol for several times to remove organic substances and reused for the next run. The performance of the recycled catalyst was tested up to five successive runs and observed that the recovered catalyst could be used for five times without an appreciable loss of its activity (Fig. 6). 
Table 3 Synthesis of spiroannulated pyrimidophenazines

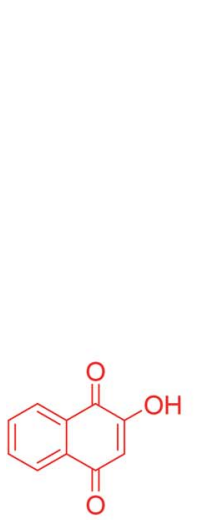

(1)

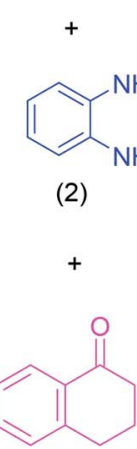

(3b)

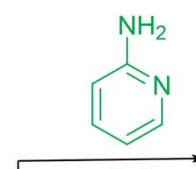

(4a)

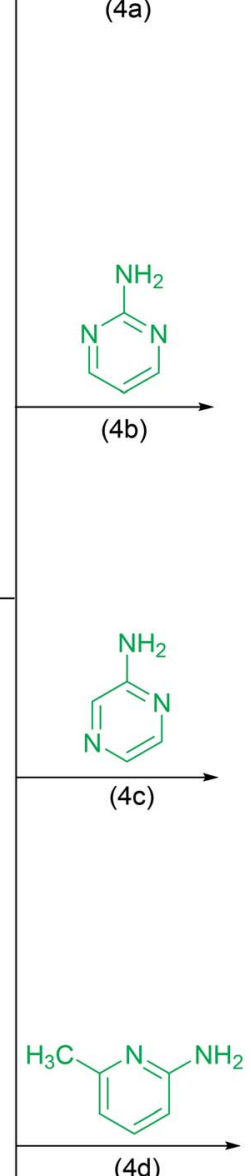

$(4 d)$

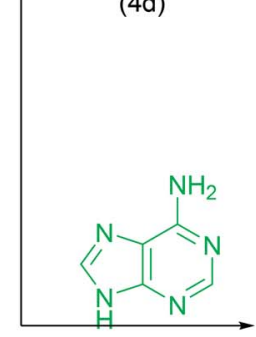

$(4 e)$<smiles>CC(C)(C)C</smiles>

(5ba)

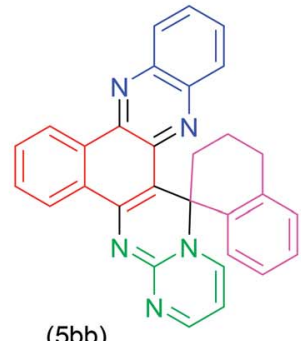

$(5 \mathrm{bb})$<smiles>C1=CN2C(=Nc3c(c4nc5ccccc5c-4nc4ccccc34)C23CCCc2ccccc23)C=N1</smiles>

(5bc)<smiles>CC1=CC=CC2=Nc3c(c4nc5ccccc5nc4c4ccccc34)C3(CCCc4ccccc43)N12</smiles>

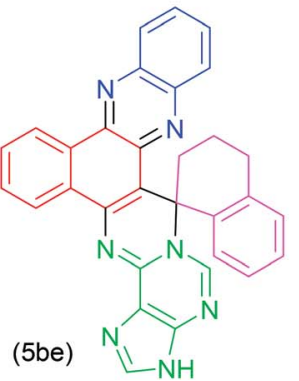

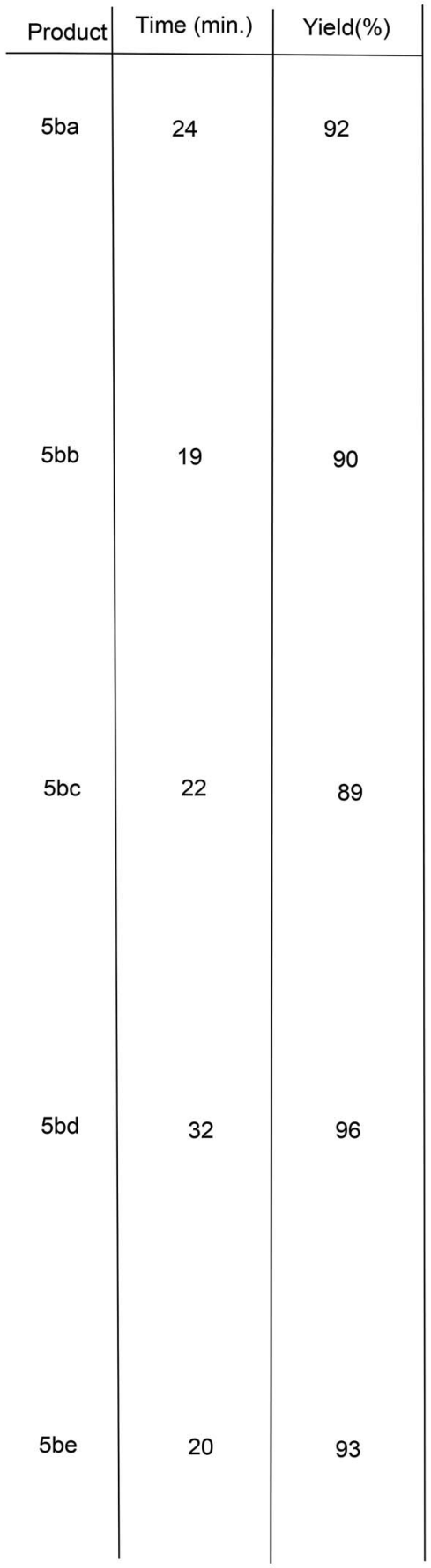

\section{Mechanism}

The mechanism of the reaction probably proceed with the following steps involving the Michael addition, cyclization and dehydration as presented in Scheme 2 (5aa). The doping of erbium with $\mathrm{TiO}_{2}$ NPs increased the efficiency of the resulting catalyst and thus facilitated the reaction in better way as compared with $\mathrm{TiO}_{2}$ NPs (Scheme 2).

\section{Experimental}

\section{General procedure}

The melting points of all the synthesized compounds were determined on electric melting point apparatus and are uncorrected. 2-Hydroxynaphthalene-1,4-dione, benzene-1,2diamine, cyclic ketones and amino derivatives used in the 
Table 4 Synthesis of spiroannulated pyrimidophenazines

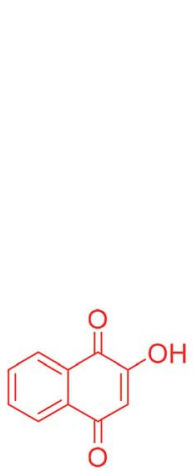

(1)

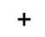<smiles>Nc1ccccc1N</smiles>

(2)

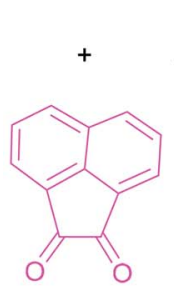

(3c)<smiles>CC(C)(C)[C@H]1C=CC=CN1C1(C(=O)c2cccc3ccccc23)c2c(c3ccccc3c3nc4ccccc4nc23)N=C2C=CC=CC21</smiles><smiles>O=C1c2cccc3cccc(c23)C12c1c(c3ccccc3c3nc4ccccc4nc13)N=C1N=CC=CN12</smiles>

$(5 \mathrm{cb})$<smiles>O=C1c2cccc3cccc(c23)C12c1c(c3ccccc3c3nc4ccccc4nc13)N=C1C=NC=CN12</smiles>

$(5 \mathrm{cc})$<smiles>CC1=CC=CC2=Nc3c(c4nc5ccccc5nc4c4ccccc34)C3(C(=O)c4cccc5cccc3c45)N12</smiles>

$(5 \mathrm{~cd})$

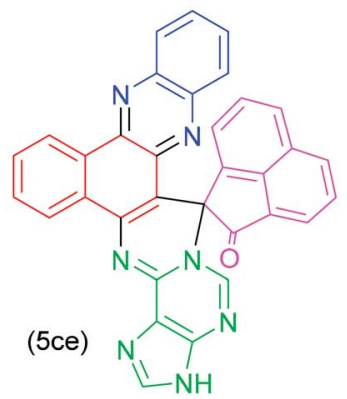

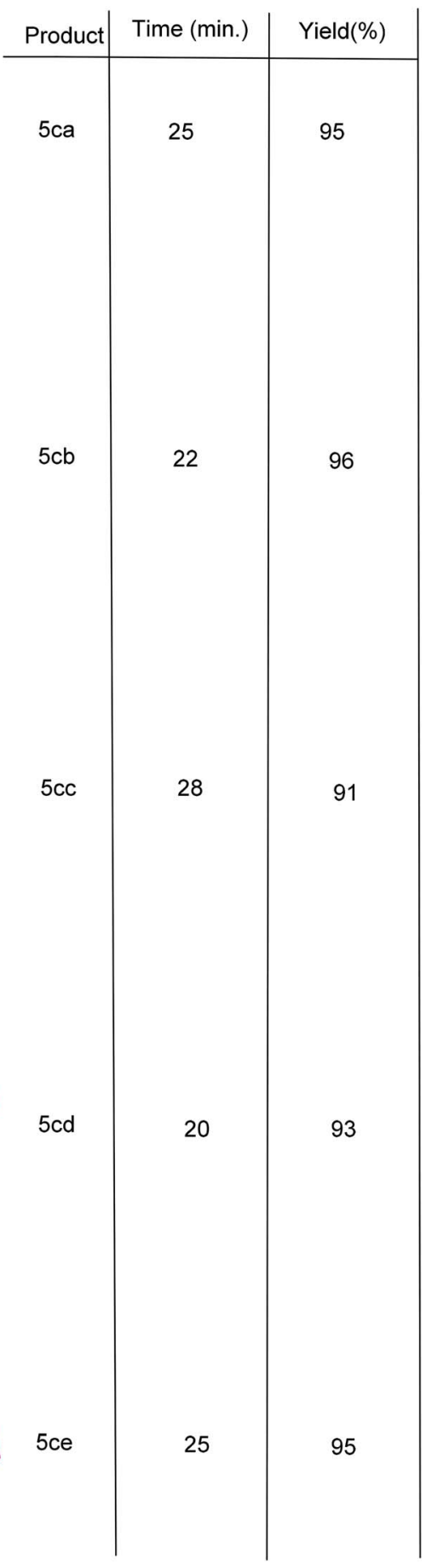

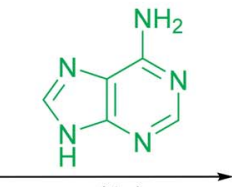

$(4 e)$ synthesis of complex spiroheterocycles were purchased from the commercial sources and were used as such. The purity of all the synthesized compounds was checked by TLC. ${ }^{1} \mathrm{H}$ NMR and ${ }^{13} \mathrm{C}$ NMR were recorded on JEOL $400 \mathrm{MHz}$ and $100 \mathrm{MHz}$ NMR spectrometer, respectively. Analytical and spectral data of the synthesized heterocycles are also included.

\section{Typical procedure for synthesis of Er doped $\mathrm{TiO}_{2} \mathrm{NPs}$}

Er doped $\mathrm{TiO}_{2}$ NPs were synthesized by sol-gel route using titanium tetra isopropoxide (TTIP) as a precursor. Firstly, water, ethanol, and acetic acid was mixed in a ratio of $2: 20: 3$ respectively and stirred for $15 \mathrm{~min}$. TTIP $(5 \mathrm{ml})$ was dissolved in the prepared solution and the stirring was continued for half an 


\section{Catalyst Recycling}

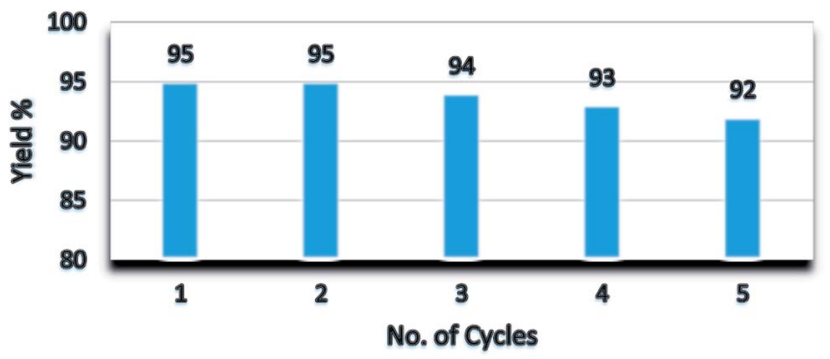

Fig. 6 Recyclability and reusability of erbium doped $\mathrm{TiO}_{2} \mathrm{NPs}$. hour. A separate solution of $\mathrm{ErCl}_{3}$ in water and ethanol (1:10) was prepared and added to the TTIP solution. The resultant solution was stirred for half an hour. 1-Thioglycerol $(0.25 \mathrm{ml})$ was added drop-wise and the stirring was further continued for next one hour. Resulted milky white sol was placed in a water bath at $80{ }^{\circ} \mathrm{C}$ for two and half hour and an orange gel was formed. Subsequently, the gel was washed with deionised water several times to eradicate the alcohol and dried in oven at $100{ }^{\circ} \mathrm{C}$. After cooling to room temperature the dried gel was grinded and the powder was post-annealed in air at the temperature $500{ }^{\circ} \mathrm{C}$ for one hour. The amount of $\mathrm{ErCl}_{3}$ was varied to synthesize Er doped $\mathrm{TiO}_{2}$ with different concentration.<smiles>O=C1C=C(O)C(=O)c2ccccc21</smiles>

(1)<smiles>Nc1ccccc1N</smiles>

(2)<smiles>O=C1Cc2nc3ccccc3nc2-c2ccccc21</smiles>

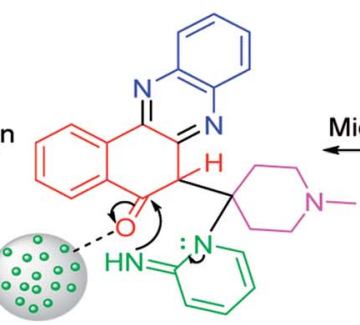
Michael addition

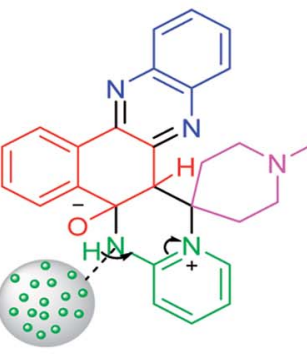

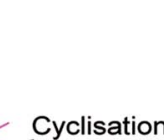

Cyclisation<smiles>[I-]</smiles>

(3a)

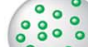<smiles>C[I+]</smiles><smiles>CN1CCC2(CC1)C1c3nc4ccccc4nc3-c3ccccc3C1(Oc1ccccc1)N=C1C=CC=CN12</smiles><smiles>CN1CCC2(CC1)c1c(c3ccccc3c3nc4ccccc4nc13)N=C1C=CC=CN12</smiles>

(5aa) 


\section{Typical procedure for synthesis of spiroheterocycles}

A mixture of 2-hydroxynaphthalene-1,4-dione ( $1 \mathrm{mmol})$, bezene1,2-diamine (1 mmol), cyclic carbonyl compounds $(1 \mathrm{mmol})$, amino derivatives $(1 \mathrm{mmol})$ and Er doped $\mathrm{TiO}_{2}$ NPs $(25 \mathrm{mg})$ in $2.0 \mathrm{ml}$ ethanol was refluxed for $20 \mathrm{~min}$. After the completion of the reaction (monitored by TLC), the catalyst was recovered by filtration, washed with ethanol, dried at room temperature and reused directly for a fresh reaction mixture up to five reaction cycle. The solid compound was purified by recrystallization from absolute ethanol without using any column chromatography.

The analytical and spectral data of the synthesized compounds have been presented and included in the ESI section. $\dagger$

\section{Conclusion}

In conclusion, we have presented highly efficient and diversity oriented sustainable domino protocol to synthesize spiroannulated pyrimidophenazines, hybrid molecules with privileged heterocyclic substructures, involving four component reaction of 2-hydroxynaphthalene-1,4-dione, benzene-1,2diamine, cyclic ketones and amino derivatives in the presence of erbium doped $\mathrm{TiO}_{2}$ NPs as recyclable and reusable heterogeneous acid catalyst. To the best of our knowledge, this is the first report where erbium doped $\mathrm{TiO}_{2}$ has been prepared and used as a heterogeneous solid acid catalyst first time for the synthesis of drug-like complex molecules incorporating medicinally privileged heterocyclic structures. The doping of $\mathrm{TiO}_{2}$ with erbium influences the efficiency of $\mathrm{TiO}_{2}$ as the catalyst and facilitates the reaction to provide comparatively better yields of the products. The present synthetic protocol offers several advantages including operational simplicity with easy work up, excellent yield with high purity, short reaction times and use of recoverable and reusable environmentally sustainable heterogeneous catalyst. The present synthetic protocol will provide an attractive synthetic methodology for the synthesis of structurally diverse drug-like small molecules for medicinal chemistry and drug discovery research.

\section{Conflicts of interest}

There are no conflicts to declare.

\section{Acknowledgements}

We gratefully acknowledge UGC New Delhi for the award of Research Fellowships to Kanchan (SRF) and Esha (JRF). UGC Bhopal is also acknowledged for financial support. Head, Department of Chemistry is acknowledged for providing Lab and instrumental facilities in the department.

\section{References}

1 S. N. Maddila, S. Maddila, W. E. van Zyl and S. B. Jonnalagadda, RSC Adv., 2015, 5, 37360-37366.
2 U. Chinna Rajesh, U. Gulati and D. S. Rawat, ACS Sustainable Chem. Eng., 2016, 4, 3409-3419.

3 B. H. Rotstein, S. Zaretsky, V. Rai and A. K. Yudin, Chem. Rev., 2014, 114, 8323-8359.

4 Z. C. Zhang, B. Xu and X. Wang, Chem. Soc. Rev., 2014, 43, 7870-7886.

5 S. K. Kundu and A. Bhaumik, RSC Adv., 2015, 5, 3273032739.

6 S. Michael Rajesh, B. D. Bala, S. Perumal and J. C. Menendez, Green Chem., 2011, 13, 3248-3254.

7 H. Naeimi, Z. Rashid, A. H. Zarnani and R. Ghahremanzadeh, New J. Chem., 2014, 38, 348-357.

8 M. B. Gawande, P. S. Branco and R. S. Varma, Chem. Soc. Rev., 2013, 42, 3371-3393.

9 B. Karami, M. Kiani, S. J. Hosseini and M. Bahrami, New J. Chem., 2015, 39, 8576-8581.

10 A. Molla and S. Hussain, RSC Adv., 2016, 6, 5491-5502.

11 G. B. Dharma Rao, S. Nagakalyan and G. K. Prasad, RSC Adv., 2017, 7, 3611-3616.

12 P. Sagar Vijay Kumar, L. Suresh, T. Vinodkumar, B. M. Reddy and G. V. P. Chandramouli, ACS Sustainable Chem. Eng., 2016, 4, 2376-2386.

13 S. N. Maddila, S. Maddila, W. E. van Zyl and S. B. Jonnalagadda, ChemistryOpen, 2016, 5, 38-42.

14 A. Amoozadeh, S. Rahmani, M. Bitaraf, F. B. Abadi and E. Tabrizian, New J. Chem., 2016, 40, 770-780.

15 C.-H. Kuo, A. S. Poyraz, L. Jin, Y. Meng, L. Pahalagedara, S.-Y. Chen, D. A. Kriz, C. Guild, A. Gudz and S. L. Suib, Green Chem., 2014, 16, 785-791.

16 Z. Zarei and B. Akhlaghinia, New J. Chem., 2017, 41, 1548515500.

17 I. Pugazhenthi, S. M. Ghouse, F.-R. Nawaz Khan, E. D. Jeong, J. S. Bae, J.-P. Kim, E. H. Chung, Y. S. Kumar and C. Dasaradhan, RSC Adv., 2015, 5, 17257-17268.

18 A. Khazaei, F. Gholami, V. Khakyzadeh, A. R. Moosavi-Zare and J. Afsar, RSC Adv., 2015, 5, 14305-14310.

19 E. Ubba, F.-R. Nawaz Khan, E. D. Jeong and E. H. Chung, RSC Adv., 2014, 4, 57016-57025.

20 S. Rana, M. Brown, A. Dutta, A. Bhaumik and C. Mukhopadhyay, Tetrahedron Lett., 2013, 54, 1371-1379.

21 Y. K. Tailor, S. Khandelwal, Y. Kumari, K. Awasthi and M. Kumar, RSC Adv., 2015, 5, 46415-46422.

22 S. Kumar, R. K. Saunthwal, M. Mujahid, T. Aggarwal and A. K. Verma, J. Org. Chem., 2016, 81, 9912-9923.

23 S. Kumar, M. Mujahid and A. K. Verma, Org. Biomol. Chem., 2017, 15, 4686-4696.

24 N. Vicker, L. Burgess, I. S. Chuckowree, R. Dodd, A. J. Folkes, D. J. Hardick, T. C. Hancox, W. Miller, J. Milton, S. Sohal, S. Wang, S. P. Wren, P. A. Charlton, W. Dangerfield, C. Liddle, P. Mistry, A. J. Stewart and W. A. Denny, J. Med. Chem., 2002, 45, 721-739.

25 H. Hussain, S. Specht, S. R. Sarite, M. Saeftel, A. Hoerauf, B. Schulz and K. Krohn, J. Med. Chem., 2011, 54, 4913-4917. 26 M. E. Makgatho, R. Anderson., J. F. O'Sullivan, T. J. Egan, J. A. Freese, N. Cornelius and C. E. J. V. Rensburg, Drug Devel. Res., 2000, 50, 195-202. 
27 N. V. Borrero, F. Bai, C. Perez, B. Q. Duong, J. R. Rocca, S. Jin and R. W. Huigens III, Org. Biomol. Chem., 2014, 12, 881-886.

28 J. R. Kerr, G. W. Taylor, A. Rutman, N. Høiby, P. J. Cole and R. Wilson, J. Clin. Pathol., 1999, 52, 385.

29 M. Conda-Sheridan, L. Marler, E.-J. Park, T. P. Kondratyuk, K. Jermihov, A. D. Mesecar, J. M. Pezzuto, R. N. Asolkar, W. Fenical and M. Cushman, J. Med. Chem., 2010, 53, 8688-8699.

30 C. Neves-Pinto, V. R. S. Malta, M. d. C. F. R. Pinto, R. H. A. Santos, S. L. de Castro and A. V. Pinto, J. Med. Chem., 2002, 45, 2112-2115.

31 N. Guttenberger, W. Blankenfeldt and R. Breinbauer, Bioorg. Med. Chem., 2017, 25, 6149-6166.

32 M. Koepf, S. H. Lee, B. J. Brennan, D. D. Méndez-Hernández, V. S. Batista, G. W. Brudvig and R. H. Crabtree, J. Org. Chem., 2015, 80, 9881-9888.

33 S. A. Gamage, J. A. Spicer, G. W. Rewcastle, J. Milton, S. Sohal, W. Dangerfield, P. Mistry, N. Vicker, P. A. Charlton and W. A. Denny, J. Med. Chem., 2002, 45, 740-743.

34 G. W. Rewcastle, W. A. Denny and B. C. Baguley, J. Med. Chem., 1987, 30, 843-851.

35 S. Funayama, S. Eda, K. Komiyama, S. Ōmura and T. Tokunaga, Tetrahedron Lett., 1989, 30, 3151-3154.

36 S. Wang, W. Miller, J. Milton, N. Vicker, A. Stewart, P. Charlton, P. Mistry, D. Hardick and W. A. Denny, Bioorg. Med. Chem. Lett., 2002, 12, 415-418.

37 B. B. Fischer, A. Krieger-Liszkay and R. I. L. Eggen, Environ. Sci. Technol., 2004, 38, 6307-6313.

38 J. M. Khurana, A. Chaudhary, A. Lumb and B. Nand, Green Chem., 2012, 14, 2321-2327.

39 P. Singh, A. Baheti and K. R. J. Thomas, J. Org. Chem., 2011, 76, 6134-6145.

40 S. Gupta and N. K. Khare, J. Mol. Struct., 2017, 1127, 309-313. 41 G. W. Rewcastle, A. J. Bridges, D. W. Fry, J. R. Rubin and W. A. Denny, J. Med. Chem., 1997, 40, 1820-1826.

42 R. B. Tenser, A. Gaydos and K. A. Hay, Antimicrob. Agents Chemother., 2001, 45, 3657-3659.

43 P. Sharma, N. Rane and V. K. Gurram, Bioorg. Med. Chem. Lett., 2004, 14, 4185-4190.

44 J. P. Cruz, T. Carrasco, G. Ortega and F. S. Cuesta, Lipids, 1992, 27, 192-194.

45 M. Hayakawa, H. Kaizawa, H. Moritomo, T. Koizumi, T. Ohishi, M. Okada, M. Ohta, S.-i. Tsukamoto, P. Parker, P. Workman and M. Waterfield, Bioorg. Med. Chem., 2006, 14, 6847-6858.

46 S. R. Natarajan, D. D. Wisnoski, S. B. Singh, J. E. Stelmach, E. A. O'Neill, C. D. Schwartz, C. M. Thompson, C. E. Fitzgerald, S. J. O'Keefe, S. Kumar, C. E. C. A. Hop, D. M. Zaller, D. M. Schmatz and J. B. Doherty, Bioorg. Med. Chem. Lett., 2003, 13, 273-276.

47 M. Font, Á. González, J. A. Palop and C. Sanmartín, Eur. J. Med. Chem., 2011, 46, 3887-3899.

48 Y. Yanagihara, H. Kasai, T. Kawashima and T. Shida, Jpn. J. Pharmacol., 1988, 48, 91-101.
49 R. L. Smith, R. J. Barrett and E. Sanders-Bush, J. Pharmacol. Exp. Ther., 1995, 275, 1050-1057.

50 F. Awouters, J. Vermeire, F. Smeyers, P. Vermote, R. van Beek and C. J. E. Niemegeers, Drug Dev. Res., 1986, 8, 95-102.

51 M. M. Badran, K. A. M. Abouzid and M. H. M. Hussein, Arch. Pharmacal Res., 2003, 26, 107.

52 D. P. Singh, S. K. Deivedi, S. R. Hashim and R. G. Singhal, Pharmaceuticals, 2010, 3, 2416-2425.

53 M. Waring, T. Ben-Hadda, A. Kotchevar, A. Ramdani, R. Touzani, S. Elkadiri, A. Hakkou, M. Bouakka and T. Ellis, Molecules, 2002, 7, 641.

54 J. A. Pereira, A. M. Pessoa, M. N. D. S. Cordeiro, R. Fernandes, C. Prudêncio, J. P. Noronha and M. Vieira, Eur. J. Med. Chem., 2015, 97, 664-672.

55 A. Monge, F. J. Martinez-Crespo, A. Lopez de Cerain, J. A. Palop, S. Narro, V. Senador, A. Marin, Y. Sainz and M. Gonzalez, J. Med. Chem., 1995, 38, 4488-4494.

56 J. B. Rangisetty, C. N. V. H. B. Gupta, A. L. Prasad, P. Srinivas, N. Sridhar, P. Parimoo and A. Veeranjaneyulu, J. Pharm. Pharmacol., 2001, 53, 1409-1413.

57 M. Kovalenko, A. Gazit, A. Böhmer, C. Rorsman, L. Rönnstrand, C.-H. Heldin, J. Waltenberger, F.-D. Böhmer and A. Levitzki, Cancer Res., 1994, 54, 61066114.

58 Y. K. Tailor, S. Khandelwal, K. Verma, R. Gopal and M. Kumar, ChemistrySelect, 2017, 2, 5933-5941.

59 Y. K. Tailor, S. Khandelwal, R. Gopal, E. Rushell, A. Prajapati and M. Kumar, ChemistrySelect, 2017, 2, 11055-11061.

60 A. Rajawat, S. Khandelwal and M. Kumar, $R S C A d v ., 2014,4$, 5105-5112.

61 A. K. Arya and M. Kumar, Green Chem., 2011, 13, 1332-1338. 62 A. Y. E. Abadi, M.-T. Maghsoodlou, R. Heydari and R. Mohebat, Res. Chem. Intermed., 2016, 42, 1227-1235.

63 A. Hasaninejad and S. Firoozi, Mol. Diversity, 2013, 17, 499513.

64 A. Yazdani-Elah-Abadi, R. Mohebat, M.-T. Maghsoodlou and R. Heydari, Polycyclic Aromat. Compd., 2018, 38, 92-101.

65 S.-L. Wang, F.-Y. Wu, C. Cheng, G. Zhang, Y.-P. Liu, B. Jiang, F. Shi and S.-J. Tu, ACS Comb. Sci., 2011, 13, 135-139.

66 P. Saluja, A. Chaudhary and J. M. Khurana, Tetrahedron Lett., 2014, 55, 3431-3435.

67 M.-T. M. Afshin Yazdani-Elah-Abadi, R. Mohebat and R. Heydari, Chin. Chem. Lett., 2017, 28, 446-452.

68 G. H. Mahdavinia, M. Mirzazadeh and B. Notash, Tetrahedron Lett., 2013, 54, 3487-3492.

69 R. Mohebat, A. Yazdani Elah Abadi and M.-T. Maghsoodlou, Res. Chem. Intermed., 2016, 42, 6039-6048.

70 R. Mohebat, A. Yazdani Elah Abadi, M.-T. Maghsoodlou and M. Mohammadi, Res. Chem. Intermed., 2016, 42, 5915-5926.

71 H. R. Shaterian and M. Mohammadnia, J. Mol. Liq., 2013, 177, 162-166.

72 R. Mohebat, A. Y. E. Abadi, M.-T. Maghsoodlou, M. Mohammadi and R. Heydari, Res. Chem. Intermed., 2016, 42, 7121-7132.

73 R. Bharti and T. Parvin, Mol. Diversity, 2016, 20, 867-876. 